\title{
A Importância da Computação para Alunos do Ensino Fundamental: Ações, Possibilidades e Benefícios.
}

\author{
Thaise de Amorim Costa $^{1}$, Fábio Cristiano Souza Oliveira ${ }^{1}$, Danielle Juliana Silva \\ Martins ${ }^{1}$, Wilson Nilo Alves da Silva ${ }^{1}$ \\ ${ }^{1}$ Instituto Federal de Educação, Ciência e Tecnologia do Sertão Pernambucano - \\ Campus Petrolina (IF-SERTÃO PE). \\ \{thaise.amorim16, fabiocristianocomp, danielle.juliana.martins, \\ nilo.alves05\} @gmail.com
}

\begin{abstract}
This paper discusses the importance of initiating computer education in basic education, and has developed activities in an extension project. The initial actions were the development of a programming course for elementary school students, in which the goal was to prepare them for the Olympiad of Informatics. Training has adopted a methodology where students are encouraged through competitions in groups and individually, solving challenges related to programming logic. The results showed that it is possible to develop computational thinking at the beginning of school education, in addition to providing digital inclusion of young people who had little access to digital technologies.
\end{abstract}

Resumo. O presente trabalho aborda a importância do ensino de computação na educação básica, e apresenta atividades desenvolvidas em um projeto de extensão. As ações iniciais consistiram no desenvolvimento de um curso de programação para alunos do ensino fundamental, no qual o objetivo era prepará-los pra a Olimpíada Brasileira de Informática. O treinamento adotou uma metodologia onde os alunos foram estimulados, através de competições em grupos e individual, resolvendo desafios relacionados à lógica de programação. Os resultados mostraram que é possível desenvolver o pensamento computacional já no início da formação escolar, além de proporcionar a inclusão digital de jovens em situação de vulnerabilidade social.

\section{Introdução}

Em uma era imersa em novas tecnologias, é importante que a inclusão digital ocorra sem distinção de idade ou publico. O processo de inclusão digital pode ser iniciado nos primeiros anos da formação escolar. Para Sica (2011), o pensamento computacional e o raciocínio lógico deveriam ser ensinados desde cedo, já que aumentam a capacidade de dedução e conclusão de problemas. Tal ação tem sido incentivada pela Sociedade Brasileira de Computação ${ }^{1}$, que defende o ensino da computação desde o Ensino

\footnotetext{
${ }^{1}$ Disponível em: <http://www.sbc.org.br/> Acesso em: mai. 2016
} 
Fundamental, a exemplo de outras ciências como, por exemplo, Física, Matemática, Química, Biologia. Assim acreditamos, como Nunes (2011), que é fundamental a introdução de conceitos de Ciência da Computação na educação básica, como forma de aprimorar o raciocínio computacional das crianças, pelo seu caráter transversal a todas as ciências.

Investir em ações que auxiliem a disseminação do ensino de computação, é investir também em novas oportunidades para um público em situação de vulnerabilidade social. Assim, o mundo da tecnologia também se configura como uma forma de inclusão social. A aprendizagem da informática e o acesso às novas linguagens de comunicação e informação, não só possibilitam oportunidades econômicas de geração de renda, como também representam um importante capital social (BAGGIO, 2000).

Nessa linha, além de possibilitar processos como a inclusão digital, o ensino de programação, e outras atividades ligadas à informática, proporcionam vários benefícios aos alunos. Para Paula (2010), a computação enquanto ciência conduz o estudante a ser autônomo, propiciando a interlocução entre indivíduos. A autora ainda destaca, que ensino de programação de computadores permite ao estudante levantar hipóteses e testálas, dessa forma, favorecendo a organização do pensamento com a possibilidade de novas inferências sobre um problema proposto. Por outro lado, com a inserção do ensino de programação na educação básica, é possível mitigar problemas como a evasão em cursos de graduação relacionados a computação . Segundo Ramos et al. (2015), os estudantes geralmente produzem uma visão errada do curso de Ciência da Computação, sendo assim, os alunos ao ingressarem na universidade acabam percebendo que o curso não é bem o que esperavam.

As ações descritas por este artigo tiveram como principal objetivo, desenvolver o pensamento computacional em jovens da educação básica, através de um curso de programação de computadores, realizado durante um projeto de extensão universitária.

As seções a seguir estão divididas da seguinte forma, 2 apresenta o projeto de extensão intitulado Programadores do Futuro. 3 serão apresentados os trabalhos relacionados. 4 aborda a metodologia e as atividades desenvolvidas. 5 contempla os resultados e, e por fim, a seção 6 apresenta as conclusões.

\section{Projetos de Extensão Universitário}

Os projetos de extensão universitária são de grande importância, pois com eles é possível utilizar conhecimentos adquiridos durante a graduação em prol de uma comunidade. Para Nunes (2011), por meio da extensão, a universidade tem a oportunidade de levar à comunidade os conhecimentos de que são detentora, os novos conhecimentos produzidos pela pesquisa e normalmente divulgados com o ensino. É uma forma de a universidade socializar e democratizar o conhecimento, levando-o aos não universitários.

Nessa perspectiva, o presente trabalho irá relatar experiências obtidas durante um treinamento de programação, para alunos do $8^{\circ}$ e $9^{\circ}$ ano do ensino fundamental, no qual foi realizado através de um Projeto de Extensão do curso de Licenciatura em Computação do XXX, no ano de 2016. O objetivo principal desse artigo foi relatar 
ações que podem ser realizadas, para disseminar os conhecimentos de computação, e consequentemente promover a inclusão digital de jovens de escolas públicas. A metodologia adotada buscou incentivar os alunos através de competições em sala de aula, e assim já prepará-los para o clima de competição da OBI (Olimpíada Brasileira de Informática).

\section{Revisão de Literatura}

$\mathrm{Na}$ literatura é possível encontrar relatos de experiências, com projetos de extensão voltados para o ensino de programação na educação básica. As estratégias utilizadas pelos autores, normalmente, buscam o desenvolvimento de aulas mais lúdicas e atrativas para os alunos. Um exemplo de trabalho com essa perspectiva é o de Oliveira et al. (2014), no qual os autores buscaram promover o ensino de lógica de programação para alunos do ensino fundamental, utilizando a ferramenta Scratch, e a computação desplugada.

Outro trabalho relacionado é o de Friedrich et al. (2012), que relata experiências obtidas durante um processo de ensino de lógica de programação para crianças de sete a dez anos de idade, utilizando como meio auxiliar de ensino, o programa Logo e o projeto Lego Mindstorms. Os resultados relatados pelos autores mostram que todas as atividades do plano de ensino foram concluídas com êxito pelas crianças.

Autores como Scaico et al. (2013) justificam o ensino de programação na educação básica, pelo fato dela proporcionar benefícios aos alunos. Para ele, este tipo de educação permite o desenvolvimento de diversas capacidades, que contribuem para melhorar o raciocínio lógico dos estudantes. Além proporcionar aproximação com essa área pode gerar uma influência importante para a escolha das carreiras dos adolescentes, que por vezes é realizada com base em informações imprecisas, o que os levam à frustração e, consequentemente, à evasão dos cursos superiores.

Geraldes et al. (2014), falam em seu trabalho sobre as reflexões positivas e negativas no ensino de programação para crianças, trazendo argumentos de especialistas e educadores de como isso pode influenciar no desenvolvimento da criança.

Garcia (2008) enfatizou os benefícios sociais, uma vez que o projeto teve o intuito de atender os alunos interessados em programação de computadores, sendo em sua maioria, desprovidos de recursos financeiros para frequentar cursos particulares.

Há outros trabalhos que apontam a importância da inclusão digital, durante esse processo de incluir o ensino computação nos primeiros anos escolares. Um exemplo de trabalho nesse sentido é o de Urruth (2010), que usando a Linguagem de Programação LOGO no ensino de geometria plana, proporcionou a inclusão digital de alunos surdos do PROEJA.

\section{Metodologia}

Inicialmente foi analisado qual seria o público alvo do projeto, e concluiu-se que o mais adequado seria capacitar alunos do Ensino Fundamental da rede publica, pois são alunos com mais dificuldades de acesso as tecnologias digitais. O próximo passo foi a elaboração de cartazes e panfletos, para a divulgação do projeto nas escolas púbicas da região. Logo após a divulgação foi aberto o período de inscrição para os alunos 
V Congresso Brasileiro de Informática na Educação (CBIE 2016)

Anais do XXII Workshop de Informática na Escola (WIE 2016)

interessados em participarem do curso. A seleção dos alunos do projeto ocorreu por ordem de inscrição.

Os trabalhos com os alunos foram iniciados em fevereiro de 2016, com previsão de término em Agosto do mesmo ano, após a segunda fase da OBI. Com um total de 15 alunos, e aulas duas vezes por semana, o curso foi dividido em módulos, que serão descritos a seguir.

\subsection{Primeiro Módulo}

O primeiro módulo teve duração de quatro semanas, no qual as aulas foram introdutórias, com conceitos de lógica de programação, e a utilização da ferramenta Visualg $^{2}$ para construção dos algoritmos. Já no inicio das aulas a turma foi dividida em três grupos, esses grupos participaram de minicompetições durante todo o treinamento, essa foi a estratégia utilizada para deixar a explicação dos conteúdos, mais lúdica para os alunos. Além de que, as minicompetições contribuíram para preparar os alunos para a competição final, que é a OBI.

O roteiro das primeiras aulas seguia da seguinte forma, após a explicação, através de slides, dos conteúdos, era proposta uma atividade aos alunos. Essas atividades envolviam a resolução de exercícios sobre algoritmos, criação de fluxogramas, e minicompetições. Em uma das competições, os alunos foram divididos em grupos, onde cada grupo tinha que cumprir no menor tempo possível, o desafio "Racha a Cuca", que consistia na resolução de uma lista de charadas.

Esse primeiro módulo teve o objetivo de trabalhar a lógica de programação com os alunos, de forma lúdica e assim prepará-los para o primeiro contato com a linguagem de programação. Algo que foi possível perceber nessa primeira etapa do treinamento foi que alguns alunos tinha pouco conhecimento sobre informática ou sobre como manusear corretamente os computadores, tendo assim que dedicar a esses alunos uma atenção maior.

\subsection{Segundo Módulo}

O segundo módulo, teve duração de nove semanas, e nele os conteúdos de programação foram abordados de forma mais direta, através das aulas de programação em C. A linguagem $\mathrm{C}$ foi escolhida para o treinamento, por ela possuir sintaxe objetivas e de fácil entendimento.

Começar a desenvolver código usando linguagem $\mathrm{C}$ ou $\mathrm{C}++$ permite compreender o funcionamento de estruturas complexas de forma clara e objetiva. A linguagem ensina o programador a ter cuidado com seu código, a estruturá-lo e organizá-lo e a tratar as variáveis com atenção (CARDOSO, 2015).

Os conteúdos abordados nesse módulo foram: Bibliotecas básicas, tipos de dados, declaração de variáveis, comandos de entrada e saída, estruturas de condição, estruturas de repetição e vetores. Nessa etapa as atividades em sala continuaram com as minicompetições, tanto individuais quanto em grupo. Uma das competições em grupo

\footnotetext{
${ }^{2}$ Disponível em: <http://www.apoioinformatica.inf.br/produtos/visualg> Acesso em: mai. 2016
} 
V Congresso Brasileiro de Informática na Educação (CBIE 2016)

Anais do XXII Workshop de Informática na Escola (WIE 2016)

deste módulo foi a do "quebra-cabeça de códigos", onde os grupos tinham que montar um quebra cabeça de um código em $\mathrm{C}$, e depois explicar qual a função daquele código (Figura 1).

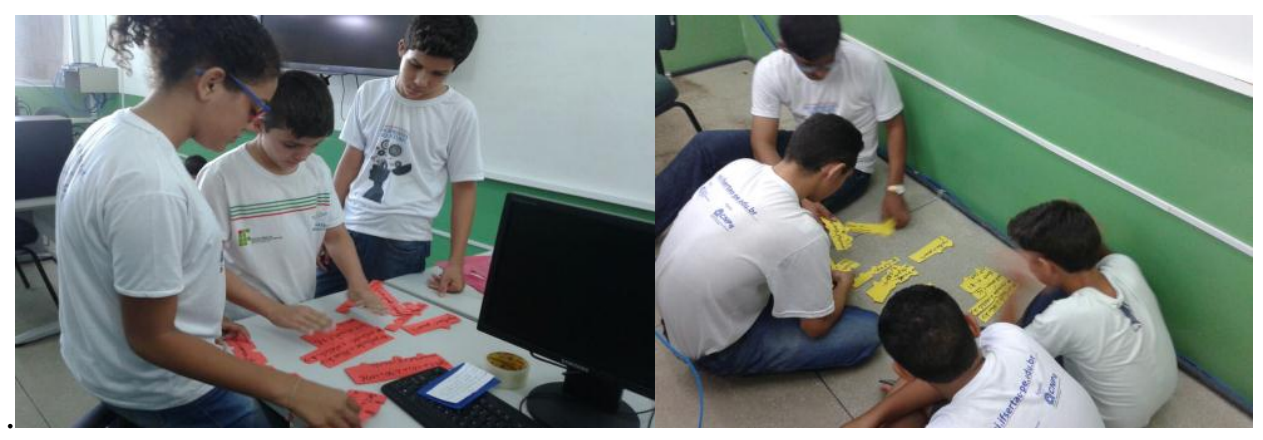

Figura 1. Competição do quebra-cabeça de códigos.

\subsection{Terceiro Módulo}

No terceiro e ultimo módulo, no qual o curso se encontra no momento, iniciou-se o processo de explicação e resolução das questões da OBI. A primeira competição deste módulo foi a maratona da OBI (Figura 2), na qual foi dividida em três etapas.

Na primeira os alunos tinham que responder uma questão da OBI de nível fácil, em 30 minutos, nessa etapa todos conseguiu terminar a questão no tempo estipulado. Na segunda etapa, eles tinham que responder uma questão de nível intermediário, em 45 minutos, nessa segunda etapa, metade da turma conseguiu terminar a questão no tempo estipulado, os restantes ultrapassaram entre 10 e 20 minutos do tempo.

Na terceira etapa, a questão era de nível difícil, e eles tinham que responder em 1 hora. Nessa ultima etapa apenas 4 alunos terminaram no tempo estipulado, 2 alunos não conseguiram terminar e os restantes ultrapassaram entre 15 e 30 minutos do tempo. 
V Congresso Brasileiro de Informática na Educação (CBIE 2016)

Anais do XXII Workshop de Informática na Escola (WIE 2016)

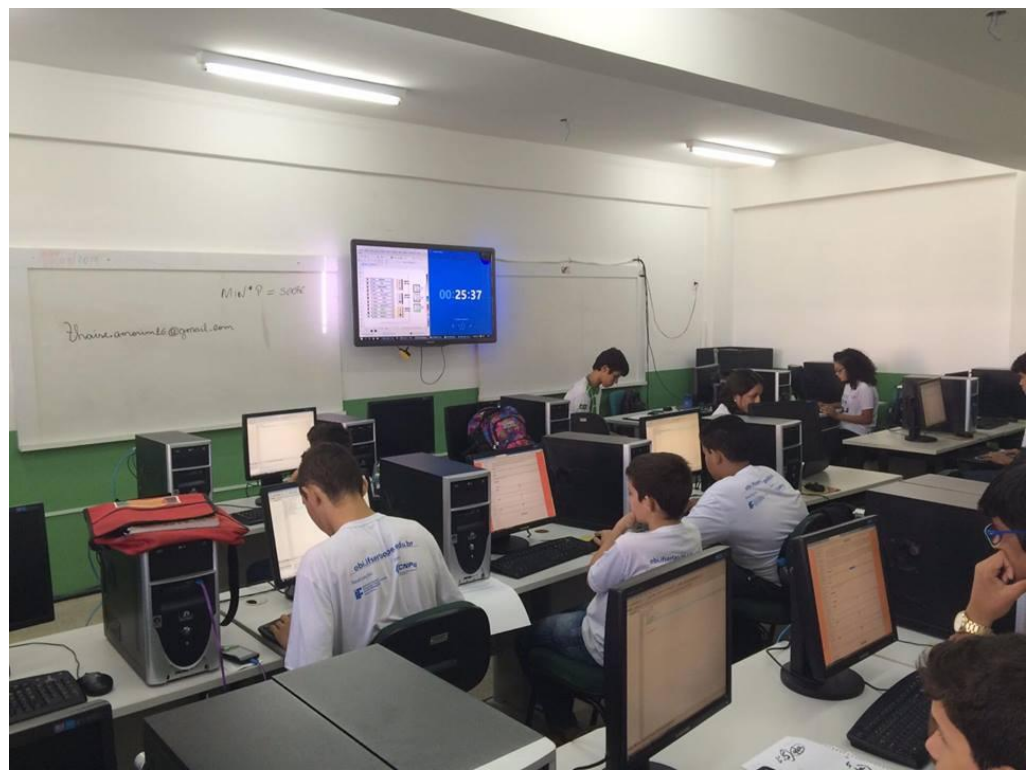

Figura 2. Atividade maratona da OBI.

Vale ressaltar, que durante a atividade descrita, o contato dos alunos com as questões da OBI, ainda era recente, mas os conhecimentos vêm sendo aprofundados através de da prática de exercícios em sala.

Ao final desse módulo, o curso terá alcançado o sétimo mês de execução, e se encerrará após a aplicação da segunda fase de provas da Olimpíada Brasileira de Informática, quando será possível quantificar os resultados, de acordo com 0 desempenho deles na prova.

\section{Resultados}

Após o primeiro módulo do curso, foi aplicado aos alunos um questionário, no qual o objetivo foi fazer uma sondagem sobre qual era o nível de contato deles, com a computação, antes de iniciar o curso, e se eles desejavam conhecer melhor a área da computação. As questões aplicadas, e os resultados serão descritos a seguir:

1. Antes de ingressar no Projeto você tinha contato diário com computadores?

2. Antes de ingressar no projeto você tinha feito algum tipo de capacitação na área de computação?

3. Com as experiências obtidas até o momento no curso, você se sente estimulado a conhecer melhor a área de computação?

4. Você concorda que os conhecimentos que serão obtidos durante o Curso, serão relevantes para sua formação?

Em relação à primeira pergunta $45 \%$ dos alunos não tinham contato frequente com computadores, até entrarem no curso e $90 \%$ dos alunos também não tinham tido nenhum tipo de capacitação na área computacional (Figura 3). O curso foi a primeira oportunidade deles de conhecerem, e estarem em contato com a computação, 
V Congresso Brasileiro de Informática na Educação (CBIE 2016)

Anais do XXII Workshop de Informática na Escola (WIE 2016)

alcançando assim um dos objetivos do projeto que é integrar os alunos ao meio computacional.

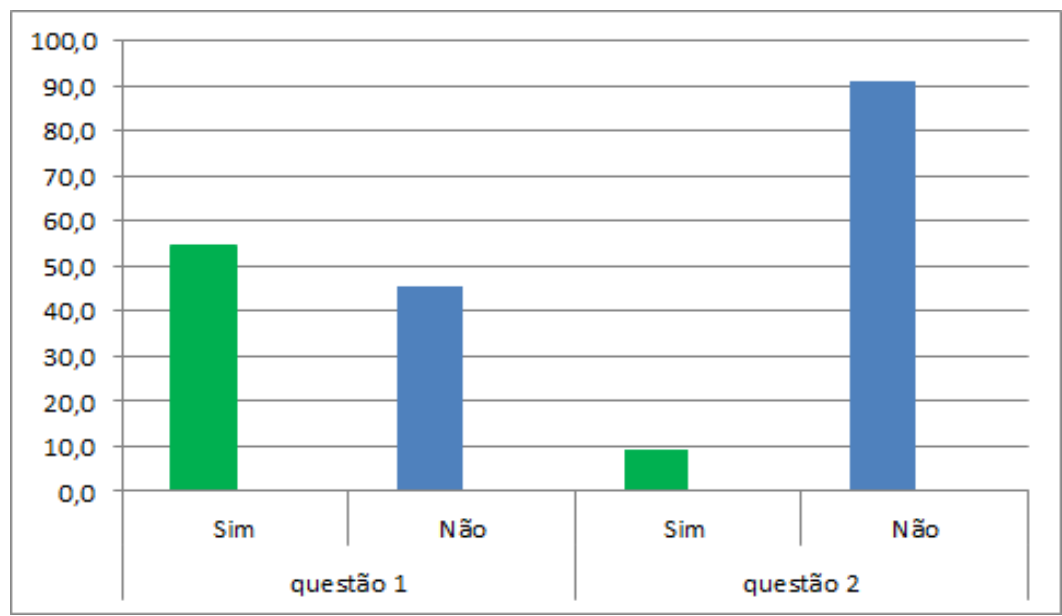

Figura 3. Gráfico com os resultados das questões 1 e 2.

O objetivo de despertar neles o interesse pela computação, também teve um resultado satisfatório (Figura 4), pois $90 \%$ dos alunos responderam ter interesse em conhecer melhor a área, e $81 \%$ concordaram que os conhecimentos obtidos no curso, serão importantes para a sua formação.

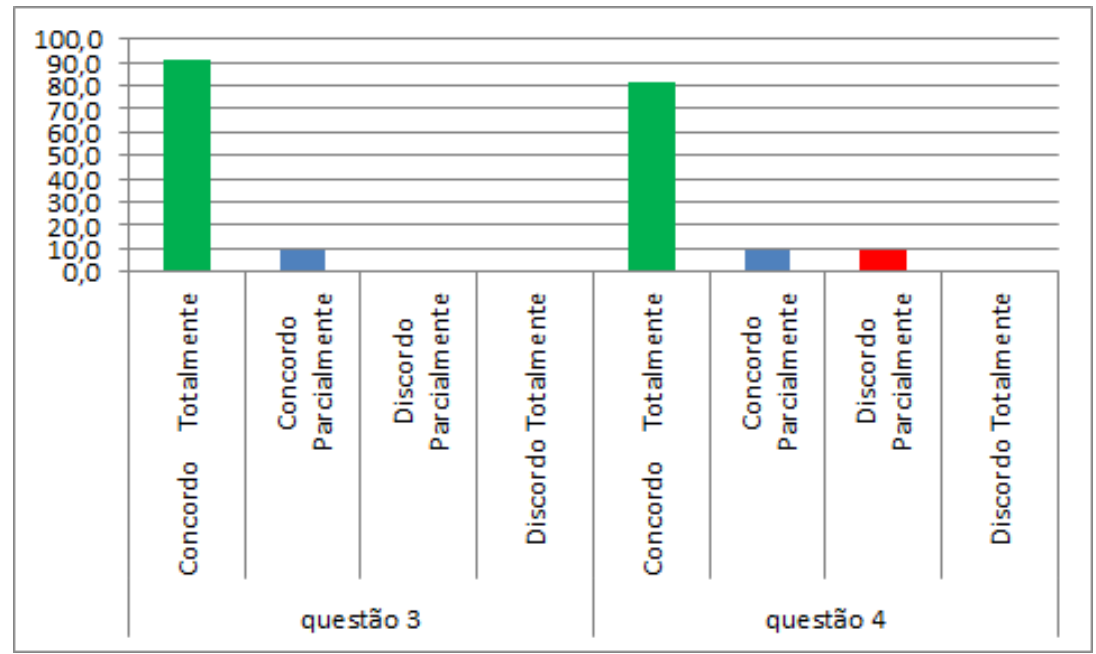

Figura 4. Gráfico com os resultados das questões 3 e 4.

\section{Conclusão}

As experiências obtidas durante o projeto mostraram que é possível, inserir o ensino de computação na Educação Básica, e disseminar a computação como ciência. As ações desenvolvidas tiveram o intuito de facilitar o processo de aprendizagem dos alunos, já que os conteúdos abordados eram incomuns ao cotidiano escolar deles. Ouve também o 
V Congresso Brasileiro de Informática na Educação (CBIE 2016)

Anais do XXII Workshop de Informática na Escola (WIE 2016)

cuidado de não deixar o processo de aprendizagem enfadonho, buscando estratégias que deixassem as aulas atrativas e divertidas, para os alunos.

Em relação aos resultados para os alunos, percebeu-se a criação de oportunidades para jovens que não tinham condições de fazer, uma capacitação como a oferecida pelo projeto. Além de que o curso deu aos alunos uma orientação vocacional, já que a maioria deseja continuar os estudo, e seguir carreira na área computacional.

As estratégias utilizadas nesse trabalho podem contribuir, para futuras ações acerca do ensino de computação na educação básica. Espera-se também que motive a execução de futuras ações que disseminem a ciência da computação nas séries iniciais da Educação. As contribuições desse trabalho para os universitários envolvidos foram $o$ aperfeiçoamento das habilidades docente, a vivência prática do que foi estudado durante a graduação, e o aprofundamento no campo de atuação.

Espera-se também que ao final do projeto, os alunos desenvolvam habilidades, e adquiram conhecimento necessário para obterem um bom resultado na OBI, e que a partir disso, surjam potenciais talentos para computação.

\section{Referencias}

BAGGIO, R. A sociedade da informação e a infoexclusão. [s.l: s.n.]. v. 29

DE OLIVEIRA, M. L. S. et al. Ensino de lógica de programação no ensino fundamental utilizando o Scratch: um relato de experiência. In: XXII Workshop sobre Educação em Computação. 2014.

FRIEDRICH, R. V. et al. Proposta Metodológica para a Inserção ao Ensino de Lógica de Programação com Logo e Lego Mindstorms. Anais do Simpósio Brasileiro de Informática na Educação, v. 23, n. 1, 2012.

GARCIA, R. E. et al. Ensino de Lógica de Programação e Estruturas de Dados para Alunos do Ensino Médio. In: XVII WEI-Workshop sobre o Ensino de Computação. Belém do Pará-PA. 2008. p. 246-249.

GERALDES,W.B. Programar é bom para as crianças? Uma visão crítica sobre o ensino de programação nas escolas. Texto Livre, Linguagem e Tecnologia. Instituto Federal de Goiás. V. $7 \mathrm{~N}^{\mathrm{o}} 2,2014$.

NASCIMENTO, M.G. et al. Competições escolares: uma alternativa na busca pela qualidade em educação. XVIII Simpósio Brasileiro de Informática na Educação. 2007.

NUNES, Daltro José. (2011). Ciência da Computação na Educação Básica. Disponível em <http://www.jornaldaciencia.org.br/Detalhe.jsp?id=79207> Acesso em: 25 de out. 2011 .

RAMOS, Thaís et al. Ensino de programação para Olimpíada Brasileira de Informática. In: Anais do Workshop de Informática na Escola. 2015. p. 122. 
V Congresso Brasileiro de Informática na Educação (CBIE 2016)

Anais do XXII Workshop de Informática na Escola (WIE 2016)

NUNES, A. L. DE P. F.; SILVA, M. B. DA C. A extensão universitária no ensino superior e a sociedadeMal-Estar e Sociedade, 2011. Disponível em: $<$ http://www.uemg.br/openjournal/index.php/malestar/article/view/60> Acesso em: 10 de mai. 2016.

SCAICO, P. D. et al. Ensino de Programação no Ensino Médio: Uma Abordagem Orientada ao Design com a linguagem Scratch. Revista Brasileira de Informática na Educação, v. 21, n. 02, p. 92, 2013.

SICA, Carlos. (2008). Ciência da Computação no Ensino Básico e Médio. Disponível em<http://www.odiario.com/blogs/carlossica/2011/10/07/ciencia-da-computacaonoensino-medio/ > Acesso em: 22 de out. de 2011.

URRUTH, Bolivar. (2010). Linguagem de Programação LOGO como Inclusão Digital no ensino de geometria plana com alunos surdos do PROEJA. Disponível em: $<$ http://www.webartigos.com/artigos/linguagem-de-programacao-logo-como-inclusaodigital-no-ensino-de-geometria-plana-com-alunos-surdos-do-proeja/49622/> Acesso em: 15 de mai. 2016.

CARDOSO, R.L. A importância da linguagem C e C++. TI Especialistas. 2015. Disponível em: http://www.tiespecialistas.com.br/2015/07/importancia-da-linguagem -c-e-c/. Acesso em: mai. de 2016. 